\title{
Factors, based on common practices, affecting the results of instrumental insemination of honey bee queens
}

\author{
Jakub GĄBKA ${ }^{1}$, Susan W. COBEY ${ }^{2}$ \\ ${ }^{1}$ Apiculture Division, Warsaw University of Life Sciences - SGGW, Nowoursynowska 166, 02-787, Warsaw, Poland \\ ${ }^{2}$ Department of Entomology, Washington State University, Pullman, WA 99164, USA
}

Received 16 February 2018 - Revised 23 June 2018 - Accepted 16 August 2018

\begin{abstract}
This study shows how the addition of a saline solution to drone semen and the pre- and postinsemination care of honey bee queens affect both the number of sperm in the spermatheca and the condition of the oviducts. Queens were instrumentally inseminated and stored under various conditions. These conditions included being held in mailing cages with 15 or 25 workers in which all were kept at $20^{\circ} \mathrm{C}$ or $34{ }^{\circ} \mathrm{C}$, and being held in nursery colonies in which the queens were caged without worker bees. Some of the queens in each group were inseminated with semen only, others were inseminated with semen and saline. The number of spermatozoa in the spermatheca did not significantly differ between the queens inseminated with semen only and those inseminated with semen and the saline solution. The queens kept in mailing cages with workers had significantly more spermatozoa than those queens banked in cages without worker bees. The addition of a saline solution to semen, and the conditions the queens were stored in, did not significantly affect the condition of the oviducts.
\end{abstract}

honey bee queens / instrumental insemination / number of spermatozoa in spermatheca / condition of oviducts

\section{INTRODUCTION}

The number of honey bee queens instrumentally inseminated annually in Poland is 50,000 to 90,000. In the rest of the world, only an estimated 6000 to 10,000 queens are inseminated instrumentally. Many factors influence the number of spermatozoa entered in the spermatheca. These factors include the age of the queen, semen dosage, and the preand post-insemination care of queens (Woyke 1962, 1979; Mackensen 1964; Woyke and Jasiński 1976, 1979, 1980, 1982; Wilde 1994; Cobey 2007; Bieńkowska et al. 2008, 2011; Cobey et al. 2013; Gąbka et al. 2016). During mass production, after insemination, queens are generally kept in mailing cages with a low number of workers. In some countries, during the pre- and post-insemination

Corresponding author: J. Gąbka,

jakub_gabka@sggw.pl

Handling editor: David Tarpy periods, queens are stored in nursery colonies in screened cages without workers. Though not optimal for sperm migration, these practices substantially reduce costs. According to Woyke (1979), there is no difference in the number of sperm in the spermatheca: of queens kept in nursery colonies in cages without workers, and of queens kept in cages with only ten workers. In their research, Woyke and Jasiński (1979) showed that instrumentally inseminated queens kept in nursery colonies in cages without workers have less spermatozoa in the spermatheca than those kept in the incubator in nursery boxes $(5.5 \mathrm{~cm} \times 12 \mathrm{~cm} \times 12 \mathrm{~cm})$ with 50 to 350 workers. They recommended holding queens for 2 days with 250 attendant bees after insemination. Similar results were obtained by Wilde (1994). Woyke and Jasiński (1980) found a very close correlation between the number of attendant workers, the temperature inside the small bee cluster in the box, and the number of spermatozoa entering the queen's spermatheca. An increase of 100 attendant workers raised the temperature of the 
bee cluster by $3.5^{\circ} \mathrm{C}$ and the number of spermatozoa entering the spermatheca by 629,000 . A temperature increase of $1{ }^{\circ} \mathrm{C}$ inside the bee cluster resulted in 170,000 more spermatozoa entering the spermatheca of the queen. Similarly, Woyke and Jasiński (1982) stated very high correlations between the same three variables when queens were kept outdoors in mating nuclei. In their study, queens did not clear semen from either oviducts when introduced to a nucleus, without previous direct contact with workers. According to Gontarz et al. (2005), queens should also be kept with attendant workers before insemination, as this period affects the condition of their oviducts after insemination. Woyke and Jasiński (1973) showed that the mean number of spermatozoa in spermatheca were significantly higher in queens kept at $34^{\circ} \mathrm{C}$ than those kept at $24{ }^{\circ} \mathrm{C}$ after insemination. On the other hand, Mackensen (1969) did not state any differences between queens kept at $25^{\circ} \mathrm{C}, 30^{\circ} \mathrm{C}$, and $35^{\circ} \mathrm{C}$.

Kaftanoglu and Peng (1980) described a washing technique for semen collection which does not require the use of a microscope. The everted bulb of the drone's endophallus is dipped into a diluent, then the semen and mucus are scraped off and washed with the aid of a small glass rod. The diluted mixture is then centrifuged to separate semen from the mucus and the diluent. This method was used and slightly modified by Moritz (1983). He collected semen using an insemination syringe, then diluted the semen, and finally, centrifuged the mixture. The purpose was to homogeneously mix semen from different drones. These methods were also modified and used in practical breeding programs (Cobey and Lawrence 1988; Kühner et al. 1989). However, Harbo (1990) found that a careful stirring of the 1:1 semen diluent, worked as well as centrifugation. The hand-stirring method has been used in different studies (Skowronek et al. 1995; Gerula et al. 2014). Usually drone semen is not diluted, unless necessary for research. In standard methods for instrumental insemination described by Cobey et al. (2013), minute amounts of saline can be added during semen collection to prevent the tip from drying out. Different saline diluent formulas are used and recommended (Mackensen 1969; Camargo 1975; Verma 1978; Williams and Harbo 1982; Moritz 1984; Harbo 1990; Cobey et al. 2013). The effect of dilution of drone semen on the number of spermatozoa entering the spermatheca was investigated by Mackensen (1969), Skowronek et al. (1995), and Gerula et al. (2016). The first author used a saline solution $(0.9 \% \mathrm{NaCl})$ or a saline solution with glucose, fructose, and trehalose $(0.1 \%$, in total), and the other authors used Hyes solution $\left(0.9 \% \mathrm{NaCl}, 0.02 \% \mathrm{CaCl}_{2}\right.$, $\left.0.02 \% \mathrm{KCl}, 0.01 \% \mathrm{NaHCO}_{3}\right)$. They employed different doses of semen, and the diluents were mixed with semen in equal proportions (1:1). None of the authors reported differences between the contents of the spermathecas of queens inseminated with semen only, and those inseminated with diluted semen. It is important to note, though, that only a small number of queens were examined in all of the above studies.

Our study is designed to investigate whether the small addition of a saline solution to drone semen and the conditions queens are held in after insemination affect both the number of spermatozoa in the spermatheca and the clearing of the oviducts. We investigated factors based on common practices used in different countries.

\section{MATERIAL AND METHODS}

The study was performed in the United States at the University of California, Davis, in 2012. We analysed 207 Italian queen bees. Larvae, less than 1 day old, were grafted to rear queens. The queens were stored in queen banks for the first 4 days following emergence, in cages without bees. Subsequently, the queens were divided into the following five groups:

1. Queens held at $20^{\circ} \mathrm{C}$ in mailing cages with 15 workers $\left(15 \mathrm{~W}-20^{\circ} \mathrm{C}\right)$;

2. Queens held at $20^{\circ} \mathrm{C}$ in mailing cages with 25 workers $\left(25 \mathrm{~W}-20{ }^{\circ} \mathrm{C}\right)$;

3. Queens held in an incubator at $34{ }^{\circ} \mathrm{C}$ in mailing cages with 15 worker bees $\left(15 \mathrm{~W}-34{ }^{\circ} \mathrm{C}\right)$;

4. Queens held in an incubator at $34{ }^{\circ} \mathrm{C}$ in mailing cages with 25 workers $\left(25 \mathrm{~W}-34{ }^{\circ} \mathrm{C}\right)$;

5 . Queens held in nursery colony banks, individually caged without bees.

The queens were inseminated at the age of 7-9 days postemergence, with semen collected from Carniolan drones. Some of the queens in each group were inseminated with semen only $(8 \mu \mathrm{l})$, others were inseminated with semen and $2 \mu$ of a saline 
solution $(8 \mu \mathrm{l}+2 \mu \mathrm{l} \mathrm{S})$. The saline contained $1 \%$ sucrose and $1 \% \mathrm{NaCl}$. An antibiotic was not used. The semen and the saline were collected into the syringe per individual queen as follows: the addition of $0.5 \mu \mathrm{l}$ of saline before the semen collection, $1 \mu \mathrm{l}$ of saline during the collection in the middle of the dose, and $0.5 \mu \mathrm{l}$ after $8 \mu \mathrm{l}$ of semen collection. After insemination, the queens were stored in the same conditions as according to their treatment groups. Worker bees in the cages were replaced with new workers. New workers were anaesthetised with carbon dioxide directly before introducing the queens. This practice prevents aggressive behaviour towards a newly introduced queen. The queens were killed after 3 days so that the condition of their oviducts could be assessed. The number of spermatozoa in their spermathecas was counted by the method described by Woyke (1979).

One- or two-way ANOVA was carried out. Significance of differences between the means was determined by the Duncan's multiple range test. The difference in the number of dead queens in each group as well as condition of the oviducts were analysed using the $\chi^{2}$ test.

\section{RESULTS}

\subsection{Queen mortality}

The mortality of queens was not significantly affected by the insemination method (undiluted semen or semen with saline solution) $\left(\chi^{2}=\right.$ $0.322, \mathrm{df}=1, p=0.570$ ) or the storage conditions $\left(\chi^{2}=4.917, \mathrm{df}=4, p=0.296\right)$. The mortality rate was $2.1 \%$ higher after insemination with undiluted semen than following insemination with semen diluted with saline. The highest percent of queens died in the $25 \mathrm{~W}-20{ }^{\circ} \mathrm{C}$ group, whereas there were no losses in the $25 \mathrm{~W}-34^{\circ} \mathrm{C}$ group (Table I).

\subsection{Number of spermatozoa in the spermatheca}

Two-way ANOVA showed that the number of spermatozoa in the spermatheca was not affected by the insemination method $\left(\mathrm{F}_{1,193}=2.146, P=\right.$ $0.145)$. However, the number was affected by the storage conditions $\left(\mathrm{F}_{4,193}=2.697, P=0.032\right)$. Interaction between the two factors was not found to be significant $\left(\mathrm{F}_{4,193}=0.694, P=0.597\right)$. On average, the queens inseminated with undiluted semen had 0.22 million (7.8\%) more spermatozoa in their spermatheca compared to queens that received diluted semen (Table II). The Duncan test revealed that queens kept outside the colony in cages containing 15 workers, at temperatures of $20^{\circ} \mathrm{C}$ and $34{ }^{\circ} \mathrm{C}$ had significantly more spermatozoa than queens caged without workers in nursery banks (Table III). In the groups of queens with $15 \mathrm{~W}-20{ }^{\circ} \mathrm{C}, 15 \mathrm{~W}-34{ }^{\circ} \mathrm{C}$, $25 \mathrm{~W}-20^{\circ} \mathrm{C}$, and $25 \mathrm{~W}-34{ }^{\circ} \mathrm{C}$, queens stored, respectively, $31,21.3,12.4$, and $13.2 \%$ more spermatozoa in their spermathecase than queens held in cages without workers in nursery colonies. No statistically significant differences were identified in the number of spermatozoa stored between the four groups of queens kept in cages with workers. Overall, all queens kept with 15 workers (at $20{ }^{\circ} \mathrm{C}$ and $34{ }^{\circ} \mathrm{C}$ ) had 3.25 million, while queens kept with 25 workers had 2.91 million sperms. Queens stored at $20^{\circ} \mathrm{C}$ and at $34{ }^{\circ} \mathrm{C}$ had 3.14 and 3.02 million spermatozoa, respectively. Altogether, queens kept outside colonies in cages with workers, had significantly more spermatozoa in their spermatheca (by 0.5 million, on average) compared to queens in nursery bank colonies caged without workers $\left(\mathrm{F}_{1,193}=7.833, P=\right.$ 0.006) (Table IV).

\subsection{Condition of oviducts}

The clearance of the oviducts was not affected by the insemination method $\left(\chi^{2}=0.392, \mathrm{df}=1\right.$, $p=0.531)$ or by the storage conditions $\left(\chi^{2}=\right.$ 3.181 , $\mathrm{df}=4, p=0.528)$. Of the queens inseminated with undiluted semen, $2.7 \%$ more had semen residue in their oviducts compared to queens inseminated with the addition of saline. The lowest number of queens with semen residue in the oviducts was observed in the $25 \mathrm{~W}-20{ }^{\circ} \mathrm{C}$ group, and the highest number in the Bank group (Table V). The number of queens with semen residue in their oviducts did not significantly differ between all the queens kept outside the colony in cages with workers and queens held in nursery banks in cages without workers $\left(\chi^{2}=1.645, \mathrm{df}=\right.$ $1, p=0.2$ ). However, the percent of queens with semen residue was two times lower in cages with attendant bees (6.7, in total) than in cages without bees (13.3). 
Table I.. Queen mortality within 3 days from instrumental insemination.

\begin{tabular}{|c|c|c|c|c|c|c|c|c|c|}
\hline \multirow{2}{*}{$\begin{array}{l}\text { Storage } \\
\text { conditions }\end{array}$} & \multicolumn{3}{|c|}{ Number of inseminated queens } & \multicolumn{3}{|c|}{ Number of dead queens } & \multicolumn{3}{|c|}{$\%$ of dead queens } \\
\hline & $8 \mu \mathrm{l}$ & $\begin{array}{l}8 \mu 1+ \\
2 \mu 1 \mathrm{~S}\end{array}$ & Overall & $8 \mu \mathrm{l}$ & $\begin{array}{l}8 \mu \mathrm{l}+ \\
2 \mu \mathrm{l} \mathrm{S}\end{array}$ & Overall & $8 \mu \mathrm{l}$ & $\begin{array}{l}8 \mu 1+ \\
2 \mu 1 \mathrm{~S}\end{array}$ & Overall \\
\hline $15 \mathrm{~W}-20^{\circ} \mathrm{C}$ & 24 & 15 & 39 & 3 & 0 & $3 a$ & 12.5 & 0 & 7.7 \\
\hline $15 \mathrm{~W}-34^{\circ} \mathrm{C}$ & 25 & 15 & 40 & 0 & 2 & $2 \mathrm{a}$ & 0 & 13.3 & 5 \\
\hline $25 \mathrm{~W}-20^{\circ} \mathrm{C}$ & 25 & 15 & 40 & 4 & 1 & $5 \mathrm{a}$ & 16 & 6.7 & 12.5 \\
\hline $25 \mathrm{~W}-34^{\circ} \mathrm{C}$ & 25 & 15 & 40 & 0 & 0 & $0 \mathrm{a}$ & 0 & 0 & 0 \\
\hline Bank & 28 & 20 & 48 & 2 & 1 & $3 \mathrm{a}$ & 7.1 & 5.0 & 6.2 \\
\hline Overall & 127 & 80 & 207 & $9 \mathrm{a}$ & $4 \mathrm{a}$ & 13 & 7.1 & 5.0 & 6.3 \\
\hline
\end{tabular}

The same letters indicate no significant differences between the groups $(P>0.05)$

Explanations:

8 - $\mu$-queens inseminated with $8 \mu \mathrm{l}$ of semen;

$8-\mu 1+2-\mu l$-S-queens inseminated with $8 \mu \mathrm{l}$ of semen and $2 \mu \mathrm{l}$ of saline solution;

$15 \mathrm{~W}-20-{ }^{\circ} \mathrm{C}$-queens kept in cages with 15 workers at $20^{\circ} \mathrm{C}$;

$15 \mathrm{~W}-34-{ }^{\circ} \mathrm{C}$-queens kept in cages with 15 workers at $34^{\circ} \mathrm{C}$;

$25 \mathrm{~W}-20-^{\circ} \mathrm{C}$-queens kept in cages with 25 workers at $20^{\circ} \mathrm{C}$;

$25 \mathrm{~W}-34-{ }^{\circ} \mathrm{C}$-queens kept in cages with 25 workers at $34^{\circ} \mathrm{C}$;

Bank: queens kept in nursery banks caged without workers

\subsection{Comparison of the number of spermatozoa in the spermatheca of queens with cleared oviducts, and the number of spermatozoa in the spermatheca of queens with semen residue}

One-way ANOVA did not show a significant effect in the condition of the queens' oviducts on the number of spermatozoa in the spermatheca $\left(\mathrm{F}_{1.193}=1.265, P=0.262\right)$. The queens with cleared oviducts had 0.31 million (11.6\%) more spermatozoa than those with semen residue (Table VI).

\section{DISCUSSION}

In this study several factors were investigated based upon common practices. We looked at the effect of adding small amounts of a saline solution to semen during the collection process. We also looked at the practices used during the pre- and post-insemination care of queens. Such practices include banking queens in nursery colonies, and storing queens in cages with small number of worker bees. According to Mackensen (1969), Skowronek et al. (1995), and Gerula et al. (2016), dilution of semen did not significantly affect the number of spermatozoa in spermathecas of queens.

Table II.. Number of spermatozoa (million) in the spermatheca of queens inseminated using different methods.

\begin{tabular}{llll}
\hline Insemination method & Number of queens & Min-max & Mean \pm SE \\
\hline $8 \mu$ l of semen & 118 & $0.78-5.67$ & $3.05 \pm 0.104 \mathrm{a}$ \\
$8 \mu \mathrm{l}$ of semen $+2 \mu \mathrm{l}$ of saline & 76 & $1.11-5.10$ & $2.83 \pm 0.107 \mathrm{a}$ \\
Overall & 194 & $0.78-5.67$ & $2.96 \pm 0.076$ \\
\hline
\end{tabular}

The same letters indicate no significant differences between the means $(P>0.05)$ 
Table III.. Number of spermatozoa (million) in the spermatheca of queens stored under different conditions.

\begin{tabular}{llll}
\hline Storage conditions & Number of queens & Min-max & Mean \pm SE \\
\hline $15 \mathrm{~W}-20{ }^{\circ} \mathrm{C}$ & 36 & $1.43-5.27$ & $3.38 \pm 0.162 \mathrm{~b}$ \\
$15 \mathrm{~W}-34{ }^{\circ} \mathrm{C}$ & 38 & $0.78-5.20$ & $3.13 \pm 0.182 \mathrm{~b}$ \\
$25 \mathrm{~W}-20{ }^{\circ} \mathrm{C}$ & 35 & $1.10-4.89$ & $2.90 \pm 0.170 \mathrm{ab}$ \\
$25 \mathrm{~W}-34{ }^{\circ} \mathrm{C}$ & 40 & $1.11-5.67$ & $2.92 \pm 0.175 \mathrm{ab}$ \\
Bank & 45 & $0.82-4.15$ & $2.58 \pm 0.144 \mathrm{a}$ \\
Overall & 194 & $0.78-5.67$ & $2.96 \pm 0.076$ \\
\hline
\end{tabular}

Different letters indicate significant differences between the means $(P<0.05)$

Explanations: as in Table I

All of the above studies used mixed semen, diluted in equal proportions. We obtained similar results but did not mix the semen volume. Moreover, we used only a small addition of the saline solution $(80 \%$ semen and 20\% saline). It should be noted that Skowronek et al. (1995) used the same amount of semen $(8 \mu \mathrm{l})$ as we did, and their results were similar. The number of spermatozoa that they found in the spermatheca of queens inseminated with diluted or undiluted semen was 3.125 and 3.48 million, respectively. We obtained 2.83 and 3.05 million, respectively. By using two semen doses of $4 \mu \mathrm{l}$ each, Gerula et al. (2016) reported the number of spermatozoa to be 4.445 and 5.126 million, respectively. In our research, after instrumental insemination, those queens kept without workers had significantly less spermatozoa in their spermathecas (2.58 million) compared to queens kept with workers (3.08 million). This confirms the investigations of Woyke and Jasiński (1979, 1982). The number of spermatozoa in the spermatheca of queens inseminated onefold with $8 \mu$ of semen and kept in small cages with workers, was similar to those obtained by others: 3.029 million (Woyke 1979), 3.181 million (Bieńkowska et al.
2008), and 3.294 million (Bieńkowska et al. 2011). It was reported by Woyke and Jasiński (1980) that queens inseminated with the same dose of semen $(8 \mu \mathrm{l})$ and kept in nursery boxes $(12 \mathrm{~cm} \times$ $12 \mathrm{~cm} \times 5.5 \mathrm{~cm}$ ) with 20 worker bees, had only 1.825 million spermatozoa in their spermathecas. Moreover, Woyke and Jasiński (1979) did not state any differences in the spermatheca content of queens that were kept in the same-sized boxes without workers, and in the spermatheca content of queens kept with 10, 20, and 40 workers. Once the number of workers was increased to 80 , however, the result was a significant increase in the number of spermatozoa in spermathecas. It seems that the number of bees in relation to the size of the cage is relevant. Probably crowding; the close contact between the queen and attendant bees, is important. This may enhance sperm migration into the spermatheca. We stated there were no significant differences between queens held in small cages with 15 attendant worker bees and those held with 25 workers. The same results were obtained by Gąba et al. (2016). The findings presented here do not show that temperature had an effect on the number of sperm in queen's spermatheca (3.144 million at

Table IV.. Number of spermatozoa (million) in the spermatheca of queens stored under different conditions.

\begin{tabular}{llll}
\hline Storage conditions & Number of queens & Min-max & Mean \pm SE \\
\hline Outside the colony in cages with workers & 149 & $0.78-5.67$ & $3.08 \pm 0.087 \mathrm{~b}$ \\
Queen bank in cages without workers & 45 & $0.82-4.15$ & $2.58 \pm 0.144 \mathrm{a}$ \\
Overall & 194 & $0.78-5.67$ & $2.96 \pm 0.076$ \\
\hline
\end{tabular}

Different letters indicate significant differences between the means $(P<0.05)$ 
Table V.. Condition of the queens' oviducts 3 days after instrumental insemination.

\begin{tabular}{|c|c|c|c|c|c|c|c|c|c|}
\hline \multirow[t]{2}{*}{$\begin{array}{l}\text { Storage } \\
\text { conditions }\end{array}$} & \multicolumn{3}{|c|}{ Number of queens } & \multicolumn{3}{|c|}{$\begin{array}{l}\text { Number of queens with semen } \\
\text { residue in oviducts }\end{array}$} & \multicolumn{3}{|c|}{$\begin{array}{l}\% \text { of queens with semen } \\
\text { residue in oviducts }\end{array}$} \\
\hline & $8 \mu \mathrm{l}$ & $\begin{array}{l}8 \mu l+ \\
2 \mu l \mathrm{~S}\end{array}$ & Overall & $8 \mu \mathrm{l}$ & $\begin{array}{l}8 \mu 1+ \\
2 \mu 1 \mathrm{~S}\end{array}$ & Overall & $8 \mu \mathrm{l}$ & $\begin{array}{l}8 \mu 1+ \\
2 \mu 1 \mathrm{~S}\end{array}$ & Overall \\
\hline $15 \mathrm{~W}-20^{\circ} \mathrm{C}$ & 21 & 15 & 36 & 3 & 1 & $4 \mathrm{a}$ & 14.2 & 6.7 & 11.1 \\
\hline $15 \mathrm{~W}-34^{\circ} \mathrm{C}$ & 25 & 13 & 38 & 1 & 1 & $2 \mathrm{a}$ & 4 & 7.7 & 5.3 \\
\hline $25 \mathrm{~W}-20^{\circ} \mathrm{C}$ & 21 & 14 & 35 & 1 & 0 & $1 \mathrm{a}$ & 4.8 & 0 & 2.9 \\
\hline $25 \mathrm{~W}-34^{\circ} \mathrm{C}$ & 25 & 15 & 40 & 2 & 1 & $3 \mathrm{a}$ & 8 & 6.7 & 7.5 \\
\hline Bank & 26 & 19 & 45 & 4 & 2 & $6 a$ & 15.4 & 10.5 & 13.3 \\
\hline Overall & 118 & 76 & 194 & $11 \mathrm{a}$ & $5 \mathrm{a}$ & 16 & 9.3 & 6.6 & 8.2 \\
\hline
\end{tabular}

The same letters indicate no significant differences between the groups $(\mathrm{P}>0.05)$

Explanations: as in Table I

$20^{\circ} \mathrm{C}$ and 3.021 million at $34^{\circ} \mathrm{C}$ ). This confirms the results obtained by Mackensen (1969). He did not state any differences between $25^{\circ} \mathrm{C}, 30^{\circ} \mathrm{C}$, and $35^{\circ} \mathrm{C}$. The opposite was noted by Woyke (1973). In their experiment, queens kept in cages with ten workers at $24^{\circ} \mathrm{C}$ had significantly less spermatozoa (3.151 million) than when kept at $34{ }^{\circ} \mathrm{C}(3.959$ million). The proportion of spermatozoa injected into the oviducts entered the spermatheca of queens kept at $24{ }^{\circ} \mathrm{C}$ and $34{ }^{\circ} \mathrm{C}$ was $5.6 \%$ and $7.0 \%$, respectively. However, their sample size was small; only 21 queens. We counted spermatozoa in the spermathecas of 194 queens. In our experiment, we found that 3 days after insemination, queens with cleared oviducts stored more spermatozoa than those queens with semen residue, but the difference was not statistically significant. Similar results were obtained by Bieńkowska and Panasiuk (2006). We found that among queens kept in cages with workers, $6.7 \%$ had semen residue in their oviducts. Of those kept in queen banks in cages without worker bees, $13.3 \%$ of queens had a semen residue in their oviducts. The difference is twice as much, but still not statistically significant. In the experiment of Woyke and Jasiński (1982), none of the queens introduced after instrumental insemination to a nucleus without direct contact with workers, cleared the semen from their oviducts. This may be an effect of crowding. Contact with attending workers may stimulate the process of clearing the semen residue from the queen's oviducts. The percent of queens with semen residues in their oviducts is lower than 39\% as reported by Bieńkowska and Panasiuk (2006), and 15.7 and 38\% as reported by Bieńkowska et al. (2008, 2011), among queens inseminated with the same dose of semen (onefold $8 \mu \mathrm{l})$ and kept in cages with 25 workers. The percent of dead queens 3 days after insemination (6.3\%), was similar to the results obtained by others: 7.9\% (Bieńkowska and Panasiuk 2006), $3.1 \%$ (Bieńkowska et al. 2008), and 2.6\% (Bieńkowska et al. 2011). On the basis of the

Table VI.. The number of spermatozoa (million) in the spermatheca of those queens with cleared oviducts and the number of spermatozoa in those queens with semen residue.

\begin{tabular}{llll}
\hline Condition of oviducts & Number of queens & Min - Max & Mean \pm se \\
\hline Cleared & 178 & $0.78-5.67$ & $2.99 \pm 0.078$ a \\
Semen residue & 16 & $0.82-4.64$ & $2.68 \pm 0.307 \mathrm{a}$ \\
Overall & 194 & $0.78-5.67$ & $2.96 \pm 0.076$ \\
\hline
\end{tabular}

The same letters indicate no significant differences between the means $(P>0.05)$ 
obtained results, we recommend to inseminate queens with undiluted semen and keep them in cages with attendant bees rather than in queen banks in cages without workers.

\section{ACKNOWLEDGEMENTS}

The authors wish to thank Professor Jerzy Woyke for his help in arranging the scientific cooperation. The 3month internship of the first author in the USA was funded by Warsaw University of Life Sciences-SGGW.

\section{AUTHORS CONTRIBUTION}

JG and SWC conceived and designed the experiments; JG performed experiments and conducted data analysis and interpretation; JG and SWC wrote the paper. Both authors read and approved the final manuscript.

\section{CONFLICT OF INTEREST}

The authors declare that they have no potential conflict of interest in relation to the study in this paper.

\section{OPEN ACCESS}

This article is distributed under the terms of the Creative Commons Attribution 4.0 International License (http://creativecommons.org/licenses/by/4.0/), which permits unrestricted use, distribution, and reproduction in any medium, provided you give appropriate credit to the original author(s) and the source, provide a link to the Creative Commons license, and indicate if changes were made.

Reines d'abeilles / insémination instrumentale / nombre de spermatozoïdes dans la spermathèque / état des oviductes

Faktoren die in der Praxis die Ergebnisse der instrumentellen Besamung von Königinnen der Honigbiene beeinflussen

Honigbienenköniginnen / instrumentelle Besamung / Spermienzahl in der Spermatheka / Zustand der Eileiter

\section{REFERENCES}

Bieńkowska, M., Panasiuk, B. (2006) Influence of the diameter of the inseminating needle tip on the results of bee queens' fertilization. J. Apic. Sci. 50 (2), 137-145

Bieńkowska, M., Wegrzynowicz, P., Panasiuk, B., Gerula, D., Loc, K. (2008) Influence of the age of honey bee queens and dose of semen on condition of instrumentally inseminated queens kept in cages with 25 worker bees in bee colonies. J. Apic. Sci. 52 (2), 23-33

Bieńkowska, M., Loc, K., Panasiuk, B., Węgrzynowicz, P., Gerula, D. (2011) Effect of dose and application on the performance of instrumentally inseminated honeybee queens kept with 25 worker bees. J. Apic. Sci. 55(1), 99-109

Camargo, C. A. de (1975) Biology of the spermatozoon of Apis mellifera. I. Influence of diluents and $\mathrm{pH}$. J. Apic. Res. 14 (3/4), 113-118

Cobey, S. W., Lawrence, T. (1988) Commercial application and practical use of the Page-Laidlaw closed population breeding program. Am. Bee J. 128, 341-344

Cobey, S. W. (2007) Comparison studies of instrumentally inseminated and naturally mated honey bee queens and factors affecting their performance. Apidologie 38, 390-410

Cobey, S. W., Tarpy, D. R., Woyke, J. (2013) Standard methods for instrumental insemination of Apis mellifera queens. J. Apic. Res. 52 (4), 1-18

Gąbka, J., Muszyńska, R., Zajdel, B. (2016) Number of spermatozoa in the spermatheca of honey bee queens inseminated with small doses of semen and kept in an incubator in cages with different numbers of workers. Med. Weter. 72 (8), 488-490

Gerula, D., Węgrzynowicz P., Panasiuk B., Bieńkowska M., Skowronek W. (2014) Performance of bee colonies headed by queens instrumentally inseminated with semen of drones who come from a single colony or many colonies. J. Apic. Sci. 58(2), 87-97

Gerula D., Wegrzynowicz, P., Panasiuk, B., Bieńkowska, M., Skowronek, W. (2016) Productivity and longevity of honey bee queens inseminated with freshly collected and diluted semen. J. Apic. Res. 55(2), 130-136

Gontarz, A., Bieńkowska, M., Loc, K. (2005) Effect of queen caging conditions on insemination results. J. Apic. Sci. 49 (1), 5-15

Harbo, J.R. (1990) Artificial mixing of spermatozoa from honeybees and evidence for sperm competition. J. Apic. Res. 29, 151-158

Kaftanoglu, O., Peng, Y.-S. (1980) A washing technique for collection of honeybee semen. J Apic. Res. 19(3), 205-211

Kühnert, M.E., Carrick, M.J., Allan, L.F. (1989) Use of homogenized drone semen in a bee breeding program in Western Australia. Apidologie 20, 371-381

Mackensen, O. (1964) Relation of semen volume to success in artificial insemination of queen honey bees. $\mathrm{J}$. Econ. Entomol. 57 (4), 581-583 
Mackensen, O. (1969) Effect of diluents and temperature on instrumental insemination of queen honey bees. J. Econ. Entomol. 62 (6), 1370-1372

Moritz, R.F.A. (1983) Homogeneous mixing of honeybee semen by centrifugation. J. Apic. Res. 22, 205-211

Moritz, R.F.A. (1984) The effect of different diluents on insemination success in the honeybee using mixed semen. J. Apic. Res. 23, 164-167

Skowronek, W. Kruk, C., Loc, K. (1995) The insemination of queen honeybees with diluted semen. Apidologie 26, 487-493

Verma, L. R. (1978) Biology of honeybee (Apis mellifera L.) spermatozoa 1. Effect of different diluents on motility and survival. Apidologie 9 (3), 167-174

Wilde, J. (1994) The effects of keeping queen honey bees after instrumental insemination on their performance. Acta Acad. Agric. Tech. Olst. Zoot. 39, 153-166

Williams, J., Harbo, J. R. (1982) Bioassay for diluents of honey bee semen. Ann. Entomol. Soc. Am. 75 , 457-459

Woyke, J. (1962) Natural and artificial insemination of queen honey bees. Bee Wld 43 (1), 21-25
Woyke, J. (1979) Effect of the access of worker honeybees to the queen on the results of instrumental insemination. J. Apic. Res. 18(2), 136-143

Woyke, J., Jasiński Z. (1973) Influence of external conditions on the number of spermatozoa entering the spermatheca of instrumentally inseminated honeybee queens. J. Apic. Res. 12 (3), 145-151

Woyke, J., Jasiński, Z. (1976) The influence of age on the results of instrumental insemination of honeybee queens. Apidologie 7 (4), 301-306

Woyke, J., Jasiński, Z. (1979) Number of worker bees necessary to attend instrumentally inseminated queens kept in incubator. Apidologie 10 (2), 149-155

Woyke, J., Jasiński, Z. (1980) Influence of the number of attendant workers on the results of instrumental insemination of honeybee queens kept at room temperature. Apidologie 11 (2), 173-180

Woyke, J., Jasinski, Z. (1982) Influence of the number of attendant workers on the number of spermatozoa entering the spermatheca of instrumentally inseminated queens kept outdoors in mating nuclei. J. Apic. Res. 21, 129-133 